\title{
Strategic alignment of IT and human resources: Testing a mediation model of e-HRM in manufacturing SMEs
}

\author{
François L'Écuyer \\ Université du Québec en Abitibi-Témiscamingue \\ francois.lecuyer@uqat.ca \\ Bruno Fabi \\ Université du Québec à Trois-Rivières \\ bruno.fabi@uqtr.ca
}

\author{
Louis Raymond \\ Université du Québec à Trois-Rivières \\ louis.raymond@uqtr.ca \\ Sylvestre Uwizeyemungu \\ Université du Québec à Trois-Rivières \\ sylvestre.uwizeyemungu@uqtr.ca
}

\begin{abstract}
Within the manufacturing sector, small and mediumsized enterprises (SMEs) face specific challenges with regard to their strategic human resource management (SHRM) capabilities. In this context, an emerging issue for both IS and HR researchers and practitioners regards e-HRM, i.e. the deployment of strategic IT capabilities to enable the firm's SHRM capabilities and thus improve its SHRM performance. In addressing this issue, the present paper aims to validate a research model that takes a moderation perspective of strategic alignment in relating SHRM and e-HRM capabilities to SHRM performance. To do so, a survey study of 206 manufacturing SMEs was realized. Results confirming the hypothesized relationships between the firm's SHRM capabilities, e-HRM competencies, e-HRM infrastructure and SHRM performance thus constitute a valid basis for prediction and prescription with regards to the strategic alignment of IT resources and human resources.
\end{abstract}

\section{Introduction}

In the last two decades, manufacturing SMEs (small and medium-sized enterprises) have been facing multiple management challenges in the face of globalization, including the strategic human resource management (SHRM) challenge [1,2,3]. In the context of a "talent war" linked to an aging workforce and with the emergence of Web 2.0-based technology such as social media, the need to recruit, retain and develop human resources (HR) requires these firms to perform better in terms of SHRM [4,5], and in particular to deploy and use IT for this purpose [6]. Furthermore, the IT-enabled management of HR, or $e-H R M$ as it is now termed, is expected to help improve their performance and competitiveness [7]. We must thus question the potential effect of e-HRM technology adoption and assimilation on the HR function's capacity to improve its performance [8], and thus better meet the strategic needs of manufacturing SMEs in this regard [9].

Given that e-HRM research to-date has mainly pertained to large organizations with an established HR function, it is necessary to adopt a different frame of reference that accounts for the specificities of SMEs with regards to the strategic management of IT resources and HR [10]. Moreover, the implementation of strategic or "mission-critical" IT such as e-HRM pose a great risk to these organizations [11], especially in terms of failing to meet SHRM objectives. A deeper understanding of the role played by e-HRM capabilities in enabling the HR function in these firms is also required, given that e-HRM research is relatively recent and consists mainly of conceptual or prescriptive research aimed at developing frameworks and guidelines for large enterprises and public organizations [10]. The relationship between e-HRM and SHRM thus remains to be further studied empirically in the specific context of SMEs, if one is to provide a better explanation of their complementary effect on SHRM performance in these enterprises. Such an analysis requires mobilizing both IS and HRM research findings in an interdisciplinary manner [12]. Now, given that ITrelated studies in both fields have generally been conducted in a disciplinary fashion, the performance effects of IT-HR complementarities have yet to be fully understood.

With the present study, we aim to contribute to the body of research on the joint effects of IT and non-IT resources in general $[13,14,15]$, and of IT capabilities and HR capabilities in particular $[16,17]$. We do so by analysing these effects from a resource and capabilitybased view [18], so as to answer the following research question: In what manner and to what extent do e-HRM capabilities of manufacturing SMEs contribute to their SHRM performance? 


\section{Conceptual Framework}

The conceptual framework of this study is primarily founded upon the resource-based view and especially upon a capability-based view (CPV) with the concepts of organizational resources and competencies that pertain to both SHRM and e-HRM. Managers can create an economic rent for their firm by being more effective than their rivals at selecting HR and IT resources or by being more effective in deploying such resources [18]. As it applies to both the HR function and the IT function in the organization, the CBV thus focuses on the managers' role in selecting, developing, combining and deploying HR and IT resources rather than on the firm's positioning in its business environment $[19,20]$. Organizational capabilities refer to the firm's "capacity to deploy" its resources and "are based on developing, carrying, and exchanging information through the firm's human capital" [21, p. 35]. These capabilities may be developed and hence observed both in functional areas (such as HR and IT) and at the corporate level [22].

\subsection{SHRM capabilities}

From a capability-based perspective that originates in the CBV, the firm capabilities for SHRM are defined as the firm's capacity to acquire, develop, and deploy human resources through a dynamic HR architecture in order to achieve a higher level of organizational performance in a complex and changing environment [23]. Research on HRM capabilities has focused on the HRM practices that are deemed to be most effective, that is, on high-performance work systems (HPWS), and has assessed their actual effect on organizational performance $[24,25,26]$. Now, SHRM capabilities in the form of HPWS are meant to allow the firm to offer a rich work environment and thus lead to greater strategic performance of the HR function in terms of greater employee satisfaction and commitment and lesser intent to quit $[2,27]$.

SHRM capabilities are the non-IT resources deemed most critical in their capacity to be enabled by IT capabilities [17]. In this regard, two strategic management mechanisms allow a firm to gain and sustain a competitive advantage: resource-picking and capability-building [18]. As the firm's HR are considered to be the key factor in both mechanisms, competent employees are thus needed to select and deploy the appropriate IT resources and to develop the required IT capabilities.

\section{2 e-HRM Capabilities}

The firm's e-HRM capabilities are defined here simply as the "practices and competences" that support its use of IT for HRM purposes [17, p. 764]. Now, eHRM capabilities have been shown to "have significant effects on the strategic role of HRM in organizations" [28, p. 2250]. As is the case for IT capabilities in general, e-HRM capabilities focus mainly on the eHRM competencies of members of the organization $[29,30,31]$, and members of the HR function in particular [32], and on the firm's e-HRM infrastructure which consists mainly of e-HRM technology and software application [33,34]. A number of characteristics may be used to identify the infrastructural capability of the HR function such as the e-HRM infrastructure's compatibility, flexibility, connectivity, level of integration and sophistication $[35,36]$.

Research on e-HRM capabilities has focused in particular on their capacity to enable the HR function to play a more strategic role [28], and on the effect of eHRM competencies and practices upon the effectiveness of SHRM in the organization [7,37]. Moreover, while they are based upon two different types of IT resources, the firm's e-HRM competencies and eHRM infrastructure may affect one another. For instance, previous empirical research has found that by improving the technical and behavioural capabilities of its IT personnel, the firm could build a better IT infrastructure capability [38]. It has also been found that by developing the expertise of its IT function, through improvements in its IT management capability, the firm could increase the flexibility of its IT infrastructure [31].

\section{Research Model and Hypotheses}

Given prior empirical studies on the complementarity of human resources and IT resources $[12,17]$ and on the adoption and consequences of eHRM in SMEs [39], the capability-based research model to be empirically validated in this study is presented in Figure 1. This model is essentially founded upon Jiang, Lepak, Hu and Baer's [40] mediation model-based meta-analysis of the effects of SHRM practices (in the form of HPWS) on proximal [human capital) and distal (voluntary turnover) strategic HR outcomes. Defining human capital as "the composition of employee skills, knowledge, and abilities" [40, p. 1266], these researchers found that the firm's SHRM practices were positively related to its human capital and that, in turn, the firm's human capital partially mediated the relationship between its SHRM practices and voluntary turnover. 


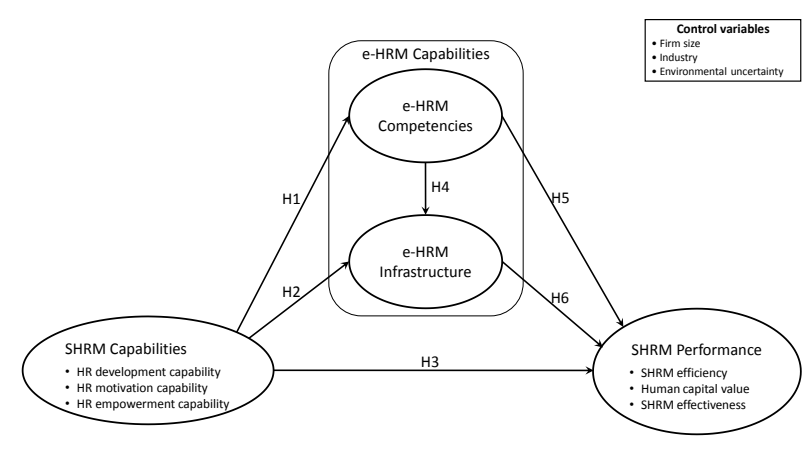

Figure 1: Research Model

Considering e-HRM to be a mechanism that mediates the influence of SHRM on organizational outcomes, we thus aim to test the following research hypotheses:

H1 - The firm's SHRM capabilities are positively related to its e-HRM competencies.

H2 - The firm's SHRM capabilities are positively related to its e-HRM infrastructure.

H3 - The firm's SHRM capabilities are positively related to its SHRM performance.

H4 - The firm's e-HRM competencies are positively related to its e-HRM infrastructure.

H5 - The firm's e-HRM competencies are positively related to its SHRM performance.

H6 - The firm's e-HRM infrastructure is positively related to its SHRM performance.

H7 - The firm's e-HRM capabilities partially mediate the positive relationship between its SHRM capabilities and SHRM performance.

Note that the last hypothesis (H7) corresponds to a "fit as mediation" perspective of the strategic alignment of e-HRM capabilities [41], and of their complementary role as IT resources vis-à-vis the firm's human resources. Three control variables are included to provide added validity to the research model. Potentially influencing the SME's development of e-HRM and SHRM capabilities as well as its SHRM performance, these variables include the firm's size [e.g. 42], industry [43], and the uncertainty of the firm's competitive, commercial and technological environment [e.g. 44].

\section{Research Method}

\subsection{Research design and sampling}

Empirical data were obtained from a questionnairebased survey. The survey population consisted of 1854 manufacturing SMEs whose number of employees ranged from 30 to 250 , selected from a repertory of all manufacturing firms in the province of Quebec, Canada. After pre-testing, the questionnaire was addressed to the person in charge of HRM in these firms. A total of 206 questionnaires were completed and usable for the analysis (11\% response rate). The greater part of the survey's respondents $(41 \%)$ held the title of human resources director (HRD) while others held titles such as HR support manager, chief financial officer, chief operational officer, president or CEO, controller and supervisor, reflecting the varied leadership and formalization of the HR function in the SME context. The mean size of the sampled firms is 81 employees, with a median of 65 . The descriptive statistics and intercorrelations of the research variables are presented in Table 1.

As generally recommended in survey research [45], the possibility of non-response bias was evaluated by comparing the responses associated with the "late" respondents, those who responded over a month after reception of the questionnaire, with the responses provided by the other ("early") respondents. After statistical comparison through t-tests, no significant differences were found between the two groups, thus indicating the absence of non-response bias. Moreover, given that the questionnaire is answered by a single respondent at one point in time, there is also a possibility of common method bias [46]. One way to evaluate the presence of such a bias is to use a "marker" variable that should not be highly correlated to any of the research variables [47]. We thus used the perceived uncertainty of the environment as the marker variable in relation with the three main research constructs, that is, e-HRM capabilities, SHRM capabilities and SHRM performance. High correlation between environmental uncertainty and the twelve indicators of the research constructs would be indicative of a common method bias. As the average correlation between environmental uncertainty and each construct's indicators was equal to 0.08 (with a maximum of 0.15 ), this last result indicates the absence of common method bias in the data.

\subsection{Measurement}

The operationalization of the research constructs is based on the extant literature. A firm endows itself with capable human resources through HR practices meant to recruit outstanding candidates, and to develop, motivate and empower them. Therefore, HR practices may be used as surrogate measures of SHRM capabilities. In line with SHRM theory and high-performance work systems, and in conjunction with the ability-motivationopportunity (AMO) framework, HR practices can be divided into three categories [27]. The presence and extent of screening, integration and development 
practices are thus used to measure the SMEs' HR development capability. Leadership, performance management, compensation and benefits practices are used to measure the HR motivation capability. And communication, participation and work-life balance practices are used to measure the HR empowerment capability.

Table 1. Descriptive Statistics and Intercorrelations of the Research Variables

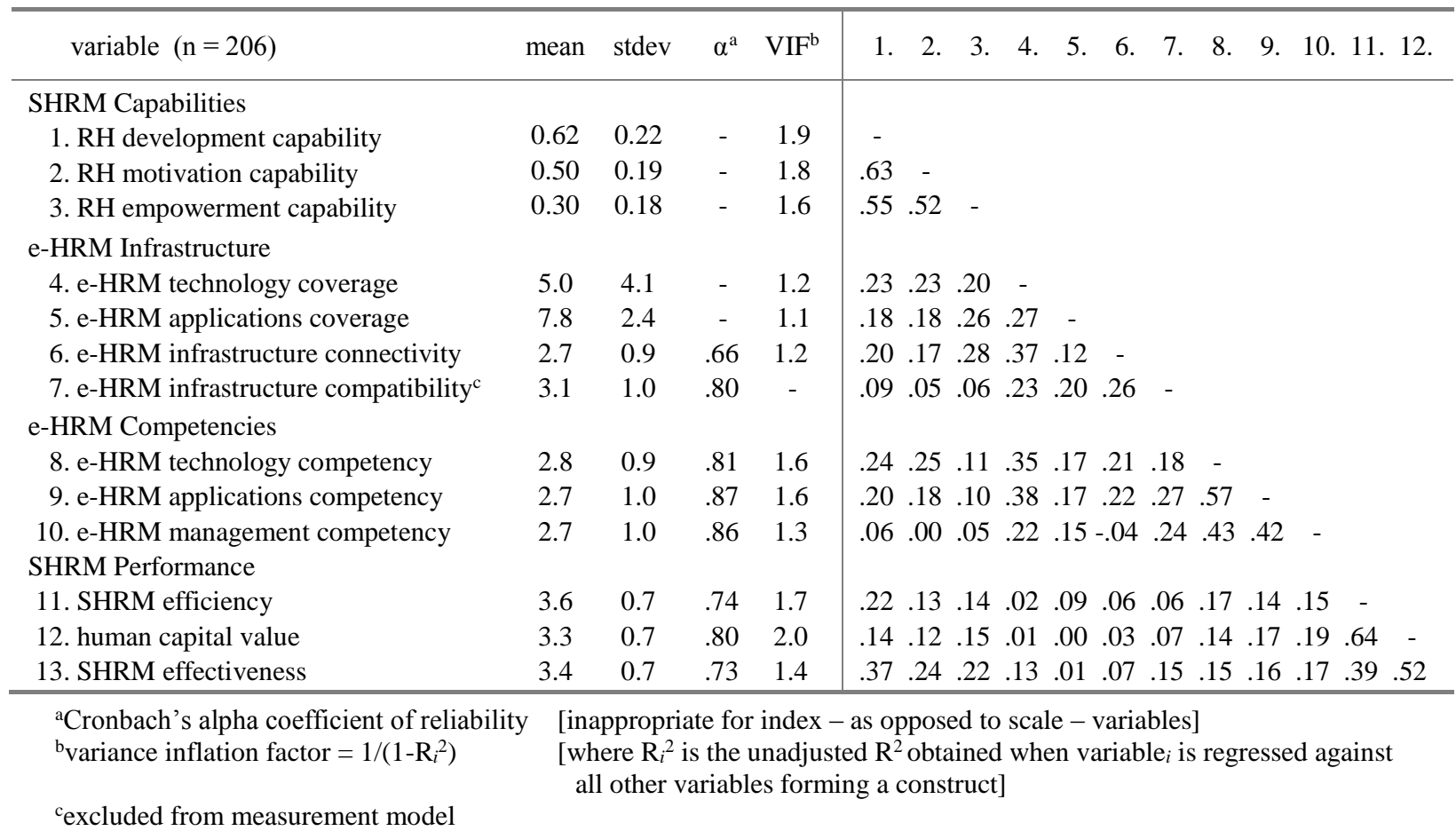

The firm's e-HRM capabilities focus on the characteristics of resources that allow it to benefit from the use of e-HRM technology and software applications. Therefore, e-HRM capabilities were operationalized through the e-HRM infrastructure and e-HRM competencies of the HR function. Two scale measures used to assess the capacity of an e-HRM infrastructure pertain to its scope and range [48]. The e-HRM infrastructure's scope refers to the connectivity between different e-HRM technologies while its range addresses the compatibility between these technologies [49]. The nine 5-point Likert scales used here to operationalize these two measures emanate from Byrd and Turner's [50] study. Two other index measures of the e-HRM infrastructure pertain to its coverage [51], operationalized as the number of e-HRM technologies (e.g. social media, self-service portals) and software applications (e.g. e-recruiting, e-performance management) that it provides [e.g. 52]. The operationalization of the SMEs' e-HRM competencies is adapted from Basselier, Benbasat and Reich's [53] study, wherein the ability of executives to promote the deployment of IT and to do so effectively constitute the two main dimensions of their IT competencies. The first means to evaluate the knowledge of SME managers in terms of e-HRM technology, e-HRM applications, involvement in the management of e-HRM and access to technological knowledge. The second evaluates their e-HRM experience and focuses on the quality of their eHRM management and their e-HRM project management in particular.

SHRM performance was operationalized along three dimensions, based on the measure proposed by Dulebohn and Johnson [54]. First assessed is the efficiency of the HR function, covering the costs and productivity of SHRM activities performed by this function with regards to certain SHRM activities such as hiring. The second dimension is assessed in terms of human capital value, that is, the value of human resources for the firm with items pertaining to the perceived costs of labor and return per employee. Finally, the third dimension is the effectiveness of the HR function in its strategic role, that is, the extent to which this function contributes to the achievement of firm's strategic goals.

As to the control variables, firm size was measured by the number of employees. Industry was assessed by the technological intensity of the industrial sector in which the firm operates (low- to medium-tech vs. medium- to high-tech), following the OECD's 
classification [55]. Environmental uncertainty was measured by adapting an instrument initially validated by Miller and Dröge [56], in which the respondent is asked to evaluate, on eight 5-point Likert scales, the degree of change and unpredictability in the firm's competitive, commercial and technological environments $(\alpha=0.68)$.

\section{Results}

The adoption rate for the e-HRM applications and technologies used by the sampled manufacturing SMEs is presented in Table 2 .

Table 2. E-HRM applications and technologies used by manufacturing SMEs $(n=206)$

\begin{tabular}{|lc|}
\hline e-HRM applications & adoption rate \\
Remuneration (salary and bonuses) & $99 \%$ \\
Time management (scheduling, timesheets) & $96 \%$ \\
Benefits & $93 \%$ \\
Development and training & $86 \%$ \\
Health and safety & $84 \%$ \\
Performance management & $83 \%$ \\
HR data analysis & $79 \%$ \\
Recruitment (selection and hiring) & $77 \%$ \\
\hline e-HRM technologies & adoption rate \\
Web sites & $65 \%$ \\
Self-service portal for managers & $44 \%$ \\
Self-service portal for employees & $41 \%$ \\
Self-service portal for HR personnel & $34 \%$ \\
Social media & $32 \%$ \\
Mobile telephony & $9 \%$ \\
\hline
\end{tabular}

Structural equation modeling was used to validate the research model, employing the PLS componentbased technique for this purpose. PLS was chosen because of its robustness and lower requirements with regard to the distribution of residues when compared to covariance-based techniques such as LISREL and EQS, in addition to being more appropriate when the goal is to explain variance $[57,58]$. PLS is also more apt to handle measurement models that include endogenous formative constructs [59]. The recommended sample size requirement for PLS is easily met here [58].

\subsection{Assessment of the measurement model}

The first step in the causal analysis is to simultaneously evaluate the measurement model and the structural model with PLS. Psychometric properties of the measurements are evaluated in the context of the structural model in assessing the unidimensionality and reliability of the research constructs. As the standard reliability and validity criteria applicable to reflective constructs do not apply to formative constructs, one must first verify that there is no multicollinearity among a formative construct's indicators. In order to do so, one uses the variance inflation factor (VIF) statistic, the rule being that the VIF must not be greater than 3.3 [60]. As shown in Table 1, VIF value for the indicators of the formative construct in the research model, e-HRM Infrastructure, were less or equal to 1.2 and thus indicates the absence of multicollinearity.

The Cronbach's $\alpha$ value for the nine indicators of the reflective constructs varied from 0.66 to 0.87 , confirming their internal consistency. As seen in Figure 2 , these indicators' loadings $(\lambda)$ are all above the 0.70 threshold, save for one at 0.65 , thus confirming the unidimensionality of the three reflective constructs in the research model. Moreover, the weights $(\gamma)$ of the formative indicators are all positive and strong enough to be retained in the measurement model, save for the "compatibility" indicator of the e-HRM Infrastructure construct which had a nonsignificant weight $(p>0.1)$ and thus was excluded from the measurement model [61]. One can also see in Table 3 that the composite reliability coefficients of the reflective constructs are between 0.84 and 1.0 , thus confirming these constructs' reliability. Also confirmed is their convergent validity as the average variance extracted (AVE) is between 0.64 and 1.0, which is above the 0.50 threshold.

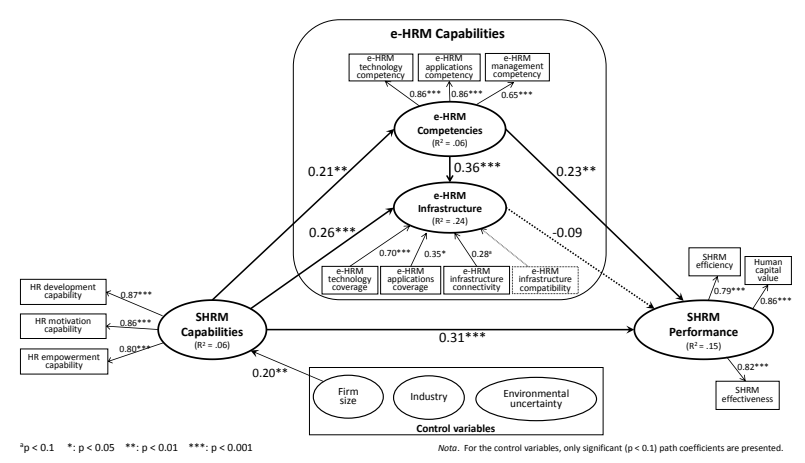

Figure 2. Test of the Research Model

The last property to be analyzed in the measurement model is discriminant validity. This property indicates the extent to which a construct differs from other constructs in the research model. In the case of reflective constructs, the shared variance between such a construct and other constructs must be less than the average variance extracted (AVE) from its indicators, as confirmed in Table 3. In the case of formative constructs, the fact that such a construct shares less than $50 \%$ variance with any other construct (inter-construct correlation inferior to 0.71 ) is evidence of such validity [62].

\subsection{Assessment of the research model}


The research model was tested by evaluating the path coefficients $(\beta)$ that links the constructs in the research model (using the SmartPLS 3.2.7 software), as shown in Figure 2. The essential quality of model fit is assessed here by the strength and significance of the path coefficients and the proportion of explained variance, as befits PLS's focus on prediction and concern with generalization [63]. Model fit may be assessed as well by the standardized root mean squared residual (SRMR) goodness-of-fit index whose value here is 0.067 , below the 0.08 threshold [58].

Table 3. Reliability, Validity and Intercorrelations of the Research Constructs $(n=206)$

\begin{tabular}{|c|c|c|c|c|c|c|c|c|c|}
\hline Construct & c.r. $^{\mathrm{a}}$ & $\mathrm{AVE}^{\mathrm{b}}$ & 1. & 2. & 3. & 4 & 5. & 6. & 7. \\
\hline 1. SHRM Capabilities & .88 & .71 & $.84^{\mathrm{c}}$ & & & & & & \\
\hline 2. e-HRM Competencies & .84 & .64 & .22 & .80 & & & & & \\
\hline 3. e-HRM Infrastructure & - & - & .41 & .41 & - & & & & \\
\hline 4. SHRM Performance & .86 & .68 & .23 & .23 & .08 & .82 & & & \\
\hline 5. Industry (tech. intensity of the sector) & 1.0 & 1.0 & .10 & .00 & .02 & -.04 & 1.0 & & \\
\hline 6. Firm size & 1.0 & 1.0 & .21 & .07 & .11 & -.03 & .07 & 1.0 & \\
\hline 7. Environmental uncertainty & 1.0 & 1.0 & .10 & .13 & .04 & -.07 & -.11 & .08 & 1.0 \\
\hline
\end{tabular}

${ }^{\mathrm{a}}$ composite reliability $=\left(\Sigma \lambda_{\mathrm{i}}\right)^{2} /\left(\left(\Sigma \lambda_{\mathrm{i}}\right)^{2}+\Sigma\left(1-\lambda_{\mathrm{i}}^{2}\right)\right)$

baverage variance extracted $=\Sigma \lambda_{\mathrm{i}}^{2} / \mathrm{n}$

c diagonal: $(\text { average variance extracted })^{1 / 2}=\left(\Sigma \lambda_{\mathrm{i}}^{2} / \mathrm{n}\right)^{1 / 2}$ sub-diagonals: correlation $=(\text { shared variance })^{1 / 2}$

Hypothesis 1 (confirmed). As shown in Figure 2, a positive and significant path coefficient $(\beta=0.21, \mathrm{p}<$ $0.01)$ confirms the hypothesis that the firm's development of stronger SHRM capabilities will lead it to increase its e-HRM competencies. It thus appears that when manufacturing SMEs improve their ability to develop, motivate and empower their human resources, these firms do so partly by improving their e-HRM competencies, that is, through increased knowledge and improved management of e-HRM technology such as social media.

Hypothesis 2 (confirmed). A positive and significant path coefficient $(\beta=0.26, \mathrm{p}<0.001)$ also confirms the hypothesized positive relationship between the firm's SHRM capabilities and its e-HRM infrastructure. Manufacturing SMEs may thus be seen here as needing to widen their use of e-HRM technologies such as employee self-service portals and mobile computing, and to increase the connectivity of these technologies in order to strengthen their HR development, motivation and empowerment capabilities.

Hypothesis 3 (confirmed). The hypothesis that developing stronger SHRM capabilities leads to improved SHRM performance is confirmed, as the corresponding path coefficient is shown to be positive and significant $(\beta=0.31, \mathrm{p}<0.001)$. This result further confirms that manufacturing SMEs develop highperformance work systems (HPWS) by being effective in selecting their human resources (resource-picking) and deploying these resources (capability building), in line with the dynamic capability-based view [19,24].

Hypothesis 4 (confirmed). Given a positive and significant path coefficient $(\beta=0.36, p<0.001)$, the hypothesis that greater e-HRM competencies lead to a [inappropriate for formative constructs]

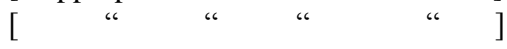

better e-HRM infrastructure is confirmed. This finding further confirms the influence of the HR function's IT competence on "championing" IT for strategic HRM purposes [53], more precisely on developing an e-HRM infrastructural capability as a co-requisite of developing a HPWS.

Hypothesis 5 (confirmed). The hypothesis that greater e-HRM competencies lead to improved SHRM performance is confirmed, as the corresponding path coefficient is found to be positive and significant $(B=$ $0.23, \mathrm{p}<0.01)$. This result highlights the critical importance for the SME's HR function, and especially for the RH manager, of developing e-HRM competencies that enable the firm's strategic HR management process.

Hypothesis 6 (unconfirmed). Given a negative and non-significant path coefficient $(\beta=-0.09)$, the hypothesis that a better e-HRM infrastructure leads to improved SHRM performance is unconfirmed. In conjunction with hypotheses 2 and 4's confirmation, one could tentatively surmise that the e-HRM infrastructure may in truth have become a SHRM capability. In other words, it may have become a constitutive element in the development of a HPWS by a manufacturing SME rather than a consequence of such a development.

The presence of a partial mediating effect of e-HRM on the SHRM $\rightarrow$ SHRM Performance relationship was first ascertained by analyzing, through a bootstrapping procedure [64], two specific indirect effect, that is, the one from SHRM Capabilities to SHRM Performance via e-HRM Competencies and the other via e-HRM Infrastructure. Infrastructure and SHRM Performance was negative and nonsignificant. As shown in Table 4, 
results indicate the first indirect effect, equal to 0.046 , is significant as its bias-corrected $95 \%$ confidence interval excludes 0 . The second indirect effect, equal to -0.025 , is nonsignificant however. In conjunction with the simpler and more powerful test of joint significance of indirect effects [65], these results partially confirm the last hypothesis in that the sampled firms' e-HRM competencies - but not their e-HRM infrastructure partially mediate the effect of their SHRM capabilities on their SHRM performance. Again, one may surmise from these last results that a strong e-HRM infrastructure is a component rather than a consequence of a high-performance work system, and thus is a capability that may be developed by manufacturing SMEs concomitantly and coherently with their HR development, motivation and empowerment capabilities, and with their e-HRM competencies.

Returning to Figure 2, the three control variables, firm size, industry and environmental uncertainty, were found to add very little explanation to the research constructs' variance, that is, to have no significant impact on SHRM capabilities, e-HRM capabilities and SHRM performance, save for the unsurprising finding that larger firms show stronger SHRM capabilities. Finally, further analysis of the data was made by testing an alternative research model, that is, one in which a moderation - rather than mediation - perspective was taken. As estimated by structural equation modeling, the moderating effects of e-HRM Competencies and eHRM Infrastructure on the SHRM Capabilities $\rightarrow$ SHRM Performance relationship were null.

Table 4. Analysis of Indirect Effects

\begin{tabular}{|c|c|c|}
\hline path $\quad(\mathrm{n}=206)$ & $\begin{array}{c}\text { indirect } \\
\text { effect }\end{array}$ & $\begin{array}{c}95 \% \\
\text { confidence }^{\text {interval }^{\mathrm{a}}}\end{array}$ \\
\hline $\begin{array}{c}\text { SHRM Capabilities } \rightarrow \\
\text { SHRM Performance } \\
\text { (via } \text { e-HRM Competencies) }\end{array}$ & 0.046 & {$[0.007,0.102]$} \\
\hline $\begin{array}{c}\text { SHRM Capabilities } \rightarrow \\
\text { SHRM Performance } \\
\text { (via } \text { e-HRM Infrastructure) }\end{array}$ & -0.025 & {$[-0.080,0.014]$} \\
\hline
\end{tabular}

abias-corrected

\section{Contribution and Implications}

The necessity to complement non-IT resources, such as HR, with IT resources in order to maintain and improve the firm's competitive position is an idea that is conceptually and practically deep-seated in the body of IS literature that is founded upon the CBV. The present study has thus contributed to furthering our knowledge of the complementary effects of two types of strategic IT and HR capabilities upon the SHRM performance of manufacturing SMEs, namely e-HRM capabilities and HPWS capabilities. This study's results suggest that the mediation approach taken here constitutes a viable theoretical alternative to the universalistic approach and to other strategic alignment perspectives such as the configurational approach [66] to capture the complementary effect of IT resources and human resources in order to understand the firm's choices in matters of SHRM and to explain its SHRM performance.

The results of this study have implications for both research and practice. To our knowledge, this is the first study to take a mediation perspective of the strategic alignment of IT and HR capabilities, and to do so by taking the HR function (instead of the organization) as the unit of analysis and its performance as the proximal outcome of alignment (instead of a distal outcome such as organizational performance). In addition, our research sheds new light on the contribution of strategic IT capabilities to SHRM performance, that is, on the mediating effect of these capabilities on the relationship between SHRM capabilities (the firm's HPWS capabilities in this case) and SHRM performance. While some authors have historically questioned the existence of a direct link between IT capabilities and performance [e.g. 67, 68], this study demonstrates that while HPWS capabilities remain as a crucial determinant of the firm's SHRM performance, manufacturing SMEs should consider their strategic use of e-HRM when developing and deploying new SHRM capabilities.

From a practical standpoint, this study raises awareness for SMEs in the manufacturing sector on the use of HR information systems to support their strategic HR management and improve their SHRM performance. One can see from our findings that developing the firm's HPWS capabilities while concomitantly developing its e-HRM capabilities results in greater improvements in SHRM performance than if the HPWS was developed alone. This suggests that the organizations that are most active in developing their IT capabilities while developing their SHRM capabilities are most likely to develop a sustained competitive advantage through their improved SHRM performance. This is especially important in a time when firms of all sizes across the globe are waging a "war for talent", that is, are battling to attract and retain human resources and are enabled to do so by using information technology [69]. Moreover, this research has identified what types of strategic IT and HR capabilities should be developed by manufacturing SMEs in order to to reach a high level of SHRM performance. For e-HRM capabilities in particular, this includes first the e-HRM competencies of the HR function's personnel and second the HR function's eHRM infrastructure in terms of technologies, applications and connectivity. 
Finally, this study's revisiting of the complementarity and joint effects of manufacturing SMEs' e-HRM and SHRM capabilities could provide the conceptual and methodological kernel for a diagnosis of the $\mathrm{HR}$ functional area in these organizations. The use and adaptation of our measurement instrument could allow managers, consultants or government agencies to jointly assess the strategic IT and HR capabilities required for the strategic development and competitiveness of SMEs in the manufacturing sector, in line with their strategic objectives.

\section{Limitations and Conclusion}

The results of this study must be interpreted with some caution due to its inherent limitations. Given the nature of the sample, its representativeness in relation to all SMEs limits the scope of these results. While comparing the strategic HR and IT management of firms in the same industry (manufacturing in our case) should be viewed as a legitimate approach, we acknowledge that the sample's homogeneity also limits the generalizability of our findings to organizations in other sectors and industries, and especially in the services sector. The research model should also be extended in future research to include factual measures of SHRM performance (such as voluntary turnover) and organizational performance, as well as potential strategic determinants of e-HRM other than SHRM capabilities (such as the SME's entrepreneurial, strategic and market orientations).

In answering its research question, our empirical investigation was able to provide a better understanding of the manner in which and the extent to which e-HRM capabilities contribute to SHRM performance in the context of manufacturing SMEs. Based upon a mediation perspective of the strategic alignment of the firm's IT resources with its human resources, the results of this study have revealed the specific e-HRM capabilities that are associated to superior SHRM performance in this context. These results support the proposition that e-HRM capabilities drive performance to the extent that they complement the SHRM capabilities of SMEs. In sustaining their competitive position within a globalized, knowledge-based economy, many manufacturing SMEs will be asked to do more and better with regard to the strategic management of their human resources. It thus behooves them to develop their SHRM and e-HRM capabilities in coherence with their strategic objectives.

\section{References}

[1] Mitchell, R., Obeidat, S. and Bray, M. (2013). The effect of strategic human resource management on organizational performance: the mediating role of high-performance human resource practices. Human Resource Management, 52(6), 899921.

[2] Ivars, J.V.P. and Martinez, J.M.C. (2015). The effect of high performance work systems on small and medium size enterprises. Journal of Business Research, 68, 1463-1465.

[3] Wu, N., Hoque, K., Bacon, N. and Bou Llusar, J. C. (2015). High-performance work systems and workplace performance in small, medium-sized and large firms. Human Resource Management Journal, 25(4), 408-423.

[4] Huselid, M. A., Jackson, S. E. and Schuler, R. S. (1997). Technical and strategic human resources management effectiveness as determinants of firm performance. Academy of Management Journal, 40(1), 171-188.

[5] Barney, J. B. and Wright, P. M. (1998). On becoming a strategic partner: the role of human resources in gaining competitive advantage. Human Resource Management, 37(1), $31-46$.

[6] Olivas-Lujan, M.R., Ramirez, J. and Zapata-Cantu, L. (2007). E-HRM in Mexico: adapting innovations for global competitiveness. International Journal of Manpower, 28(5), $418-434$.

[7] Bondarouk, T. and Ruël, H. (2012). The strategic value of e-HRM: results from an exploratory study in a governmental organization, International Journal of Human Resource Management, 24(2), 391-414.

[8] Parry, E. (2011). An examination of e-HRM as a means to increase the value of the HR function. International Journal of Human Resource Management, 22(5), 1146-1162.

[9] Schalk, R., Timmerman, V. and Van den Heuvel, S. (2013). How strategic considerations influence decision making on e-HRM applications. Human Resource Management Review, 23(1), 84-92.

[10] Marler, J. H. and Fisher, S. L. (2013). An evidence-based review of e-HRM and strategic human resource management. Human Resource Management Review, 23(1), 18-36.

[11] Poba-Nzaou, P. and Raymond, L. (2011). Managing ERP system risk in SMEs: a multiple case study. Journal of Information Technology, 26(3), 172-190.

[12] Khatri, N., Baveja, A., Agrawal, N.M. and Brown, G.D. (2010). HR and IT capabilities and complementarities in knowledge-intensive services. International Journal of Human Resource Management, 21(15), 2889-2909.

[13] Song, M., Dröge, C., Hanvanich, S. and Calantone, R. (2005). Marketing and technology resource complementarity: An analysis of their interaction effect in two environmental contexts. Strategic Management Journal, 26(1), 259-276.

[14] Jeffers, P.I., Muhanna, W.A. and Nault, B.R. (2008). Information technology and process performance: An empirical investigation of the interaction between IT and nonIT resources. Decision Sciences, 39(4), 703-735.

[15] Chen, J.-L. (2012). The synergistic effects of IT-enabled 
resources on organizational capabilities and firm performance. Information \& Management, 49(3-4), 142-150.

[16] Carte, T. and Chidambaram. L. (2004). A capabilitiesbased theory of technology deployment in diverse teams: Leapfrogging the pitfalls of diversity and leveraging its potential with collaborative technology. Journal of the Association for Information Systems, 5(11-12), 448-471.

[17] Aral, S. and Weil, P. (2007). IT assets, organizational capabilities, and firm performance: How resource allocations and organizational differences explain performance variation. Organization Science, 18(5), 763-780.

[18] Makadok, R. (2001). Toward a synthesis of the resourcebased and dynamic-capability views of rent creation. Strategic Management Journal, 22(5), 387-401.

[19] Colbert, B. A. (2004). The complex resource-based view: implications for theory and practice in strategic human resource management. Academy of Management Review, 29(3), 341-358.

[20] Wade, M. and Hulland, J. (2004). The resource-based view and information systems research: Review, extension and suggestions for future research. MIS Quarterly, 28(1), 107-142.

[21] Amit, R., \& Schoemaker, P. J. H. (1993). Strategic assets and organizational rent. Strategic Management Journal, 14(1), $33-46$.

[22] Grant, R. M. (1996). Prospering in dynamicallycompetitive environments: organizational capability as knowledge integration. Organization Science, 7(4), 375-387.

[23] Khatri, N. (2006). Building HR capability in health care organizations. Health Care Management Review, 31(1), 4554 .

[24] Becker, B. E. and Huselid, M. A. (1998). High performance work systems and firm performance: a synthesis of research and managerial implications. Research in Personnel and Human Resources Management, 16, 53-101.

[25] Fabi, B., Lacoursière, R., Raymond, L. and St-Pierre, J. (2010). HRM capabilities as a determinant and enabler of productivity for manufacturing SMEs. Human Systems Management, 29(3), 115-125.

[26] Kehoe, R.R., \& Wright, P.M. (2013). The impact of highperformance human resource practices on employee's attitudes and behaviors. Journal of Management, 39, 366-391.

[27] Fabi, B., Lacoursière, R. and Raymond, L. (2015). Impact of high-performance work systems on job satisfaction, organizational commitment, and intention to quit in Canadian organizations. International Journal of Manpower, 36(5), 772-790.

[28] Marler, J.H. and Parry, E. (2016) Human resource management, strategic involvement and e-HRM technology, International Journal of Human Resource Management, 27(19), 2233-2253.

[29] Ravichandran, T. and Lertwongsatien, C. (2005). Effect of information systems resources and capabilities on firm performance: a resource-based perspective. Journal of Management Information Systems, 21(4), 237-276.

[30] Ray, G., Muhanna, W.A. and Barney, B. (2005). Information technology and the performance of the customer service process: A resource-based analysis. MIS Quarterly, 29(4), 625-652.

[31] Kim, G., Shin, B., Kim, K.K. and Lee, H.G. (2011). IT capabilities, process-oriented dynamic capabilities, and firm financial performance. Journal of the Association for Information Systems, 12(7), 487-517.

[32] Panayotopoulou, L., Vakola, M. and Galanaki, E. (2007). E-HR adoption and the role of HRM: Evidence from Greece. Personnel Review, 36, 277-294.

[33] Hooi, L.W. (2006). Implementing e-HRM: The readiness of small and medium sized manufacturing companies in Malaysia. Asia Pacific Business Review, 12, 465-485.

[34] Reddick, C.G. (2009). Human resources information systems in Texas city governments: Scope and perception of its effectiveness. Public Personnel Management, 38, 19-34.

[35] Chung, S.H., Byrd, T.A., Lewis, B.R. and Ford, F.N. (2005). An empirical study of the relationships between IT infrastructure flexibility, mass customization, and business performance, Database for Advances in Information Systems, 36(3), 26-44.

[36] Uwizeyemungu, S. and Raymond, L. (2012). Impact of an ERP system's capabilities upon the realisation of its business value: A resource-based perspective. Information Technology and Management, 13(2), 69-90.

[37] Haines, V.Y. and Lafleur, G. (2008). Information technology usage and human resource roles and effectiveness. Human Resource Management, 47(3), 525-540

[38] Fink, L. and Neumann, S. (2007). Gaining agility through IT personnel capabilities: The mediating role of IT infrastructure capabilities. Journal of the Association for Information Systems, 8(8), 440-462.

[39] Bondarouk, T., Parry, E. and Furtmueller, E. (2017). Electronic HRM: four decades of research on adoption and consequences, International Journal of Human Resource Management, 28(1), 98-131.

[40] Jiang, K., Lepak, D.P., Hu, J., \& Baer, J.C. (2012). How does human resource management influence organizational outcomes? A meta-analytic investigation of mediating mechanisms. Academy of Management Journal, 55, 12641294.

[41] Bergeron, F., Raymond, L. and Rivard, S. (2001). Fit in strategic information technology management research: an empirical comparison of perspectives. Omega, 29(2), 125142 .

[42] Pflughoest, K., Ramamurthy, K., Soofi, E., YasaiArdekani, M. and Zahedi, F. (2003). Multiple conceptualizations of small business Web use and benefit. Decision Sciences, 34 (3), 467-512.

[43] Chiasson, M. W. and Davidson, E. (2005). Taking 
industry seriously in information systems research. MIS Quarterly, 29(4), 591-605.

[44] Zhang, M., Sarker, S. and Sarker, S. (2013). Drivers and import performance impacts of IT capability in 'born-global' firms: a cross-national study. Information Systems Journal, $23,419-443$.

[45] Hikmet, N. and Chen, S. K. (2003). An investigation into low mail survey response rates of information technology users in health care organizations. International Journal of Medical Informatics, 72(1), 29-34.

[46] Podsakoff, P. M., MacKenzie, S. B., Lee, J.-Y. and Podsakoff, N. P. (2003). Common method biases in behavioral research: a critical review of the literature and recommended remedies. Journal of Applied Psychology, 88(5), 879-903.

[47] Lindell, M. K. and Whitney, D. J. (2001). Accounting for common method variance in cross-sectional research designs. Journal of Applied Psychology, 86(1), 114-121.

[48] Keen, P. G. W. (1991). Shaping the future: business design through information technology. Cambridge, MA: Harvard Business School Press.

[49] Duncan, N. B. (1995). Capturing flexibility of information technology infrastructure: a study of resource characteristics and their measure. Journal of Management Information Systems, 12(2), 37-57.

[50] Byrd, T. A. and Turner, D. E. (2000). Measuring the flexibility of information technology infrastructure: exploratory analysis of a construct. Journal of Management Information Systems, 17(1), 167-208.

[51] Strong, D.M. and Volkoff, O. (2010). Understanding organization-enterprise system fit: A path for theorizing the information technology artifact. MIS Quarterly, 34 (4), 731 756.

[52] Strohmeier, S. and Kabst, R. (2014). Configurations of eHRM - an empirical exploration. Employee Relations, 36(4), 333-353.

[53] Basselier, G., Benbasat, I. and Reich, B. H. (2003). The influence of business managers' IT competence on championing IT. Information Systems Research, 14(4), 317336.

[54] Dulebohn, J. H. and Johnson, R. D. (2013). Human resource metrics and decision support: a classification framework. Human Resource Management Review, 23(1), 7183.

[55] Hatzichronoglou, T. (1997). Revision of the HighTechnology Sector and Product Classification (STI Working Paper Series No. 1997/2). Paris: OECD Publishing.

[56] Miller, D. and Dröge, C. (1986). Psychological and traditional determinants of structure. Administrative Science Quarterly, 31(4), 539-560.
[57] Gefen, D., Ringdon, E.E. and Straub, D. (2011). An update and extension to SEM guidelines for administrative and social science research. MIS Quarterly, 35(2), iii-xiv.

[58] Henseler, J., Hubona, G. and Ash Ray, P. (2016). Using PLS path modeling in new technology research: updated guidelines. Industrial Management \& Data Systems, 116(1), 2 20.

[59] Roberts, N. and Thatcher, J.B. (2009). Conceptualizing and testing formative constructs: Tutorial and annotated example. Data Base for Advances in Information Systems, 40(3), 9-39.

[60] Diamantopoulos, A. and Siguaw, J. (2006). Formative vs. reflective indicators in organizational measure development: A comparison and empirical illustration. British Journal of Management, 17, 263-282.

[61] Bollen, K. (2011). Evaluating effect, composite, and causal indicators in structural equation models. MIS Quarterly, 35 (2), 359-372.

[62] MacKenzie, S.B., Podsakoff, P.M. and Jarvis, C.B. (2005). The problem of measurement model misspecification in behavioral and organizational research and some recommended solutions. Journal of Applied Psychology, 90(4), 710-730.

[63] Ringle, C.M., Sarstedt, M. and Straub, D. (2012). A critical look at the use of PLS-SEM in MIS Quarterly. MIS Quarterly, 36(1), iii-xiv, S3-S8.

[64] Nizl, C., Roldan, J.L. and Cepeda, G. (2016). Mediation analysis in partial least squares path modeling: Helping researchers discuss more sophisticated models. Industrial Management \& Data Systems, 116(9), 1865-1886.

[65] Leth-Steensen, C. and Gallitto, E. (2015). Testing mediation in structural equation modeling: The effectiveness of the test of joint significance. Educational and Psychological Measurement, 76(2), 339-351.

[66] Uwizeyemungu, S., Raymond, L., Poba-Nzaou, P. and StPierre, J. (2018). The complementarity of IT and HRM capabilities for competitive performance: a configurational analysis of manufacturing and industrial service SMEs. Enterprise Information Systems, https://doi.org/10.1080/ 17517575. 2018.1448118, 1-23.

[67] Carr, N.G. (2003). IT doesn't matter. Harvard Business Review, 81(5), 41-49.

[68] Brynjolfsson, E. and Hitt L.M. (1996) Paradox lost? Firm-level evidence on the returns to information systems spending. Management Science, 42(4), 541-558.

[69] Beulen, E. (2008). The enabling role of information technology in the global war for talent: Accenture's industrialized approach. Information Technology for Development, 14(3), 213-224. 